\title{
Retraction Note: Extraction of flavonoids and kinetics of purification by macroporous resins from quinoa
}

\author{
Wu Xiaoyong • Tang Yuan • Sun Yanxia • \\ Xiang Dabing • Wan Yan - Wu Qi • Zhao Gang
}

Published online: 11 August 2021

(C) Springer Nature B.V. 2021
The Editor-in-Chief and the Publisher have retracted this article. The article was accepted as part of a guestedited special issue in Journal of Nanoparticle Research. Before the special issue was finalized, the Editor-inChief detected problems with editorial handling and peer review and decided not to proceed with the special issue [1].

Post publication peer review found that this article is out of scope for the journal, which focuses on original contributions on nanoscale phenomena and processes, and does not meet the standards required by the journal.

The online version of the original article can be found at https://doi.org/10.1007/s11051-020-04906-7

W. Xiaoyong $\cdot$ T. Yuan $\cdot$ S. Yanxia $(\bowtie) \cdot$ X. Dabing $\cdot$ W. Yan - W. Qi · Z. Gang

Key Laboratory of Coarse Cereal Processing, Ministry of Agriculture and Rural Affairs, Chengdu University, Chengdu 610106 Sichuan, China

e-mail: cduwxysyx@126.com
The corresponding author stated on behalf of all coauthors that they agree to this retraction.

\section{References}

1. Pinna, N., Clavel, G. \& Roco, M.C. the journal of nanoparticle research victim of an organized rogue editor network!. J Nanopart res 22, 376 (2020). https://doi.org/10.1007/s11051020-05094-0

Publisher's note Springer Nature remains neutral with regard to jurisdictional claims in published maps and institutional affiliations. 